\title{
FACTORS RELATED TO PSYCHOLOGICAL WELL-BEING IN UNSKILLED MANUAL WORKERS
}

\author{
JUNGSUN PARK ${ }^{1}$ and YANGHO KIM ${ }^{2}$ \\ ${ }^{1}$ Catholic University of Daegu, Gyeongsan, South Korea \\ Department of Occupational Health \\ ${ }^{2}$ University of Ulsan College of Medicine, Ulsan University Hospital, Ulsan, South Korea \\ Department of Occupational and Environmental Medicine
}

\begin{abstract}
Objectives: The authors characterized the demographic, socioeconomic, and psychosocial work factors associated with performance of unskilled manual work, and then identified the modifiable psychosocial work factors that affected the psychological well-being of these workers. Material and Methods: This study analyzed data from the fifth Korean Working Condition Survey conducted in 2017. The study subjects were 37081 Korean employees. The occupational classes investigated were: managers, professionals, and clerks; service and sales workers; and skilled or unskilled manual workers. Results: Unskilled manual workers were more likely to be elderly and less educated, to have low income, to work fewer hours weekly, to have a shorter work duration, to perform temporary or daily jobs, and to report poor subjective health and well-being. Unskilled manual workers were also more likely to experience psychosocial hazards, such adverse social behaviors, a lack of job satisfaction, a lack of support from managers, and a poor social climate. However, with statistical adjustment for demographic, socioeconomic, and psychosocial work factors, unskilled manual work was no longer associated with poor psychological well-being, but psychosocial work factors were associated with poor psychological well-being. Conclusions: The poor psychological well-being of unskilled manual workers cannot be explained by the intrinsic nature of this type of work. Instead, the poor psychological well-being of these workers is associated with unfavorable psychosocial work factors, such as a poor employment status, a lack of job satisfaction, a lack of support from managers, and a bad social climate. These results thus suggest that the modification of psychosocial work factors may improve the psychological well-being of unskilled manual workers. Int J Occup Med Environ Health. 2021;34(6):789-804
\end{abstract}

Key words:

job satisfaction, job, manual workers, psychological well-being, occupational groups, unskilled workers

\section{INTRODUCTION}

Economic globalization has contributed to significant alterations in the nature of employment throughout the world. These changes include widespread restructuring and downsizing by large private and public sector employers; changing employment status, especially a decline in the number of permanent employees and an increase in the numbers of temporary workers and self-employed subcontractors; and a growing use of outsourcing and multi-tiered subcontracting [1-3]. Thus, many individuals now work on a tempo- rary basis for $\geq 1$ of the proliferating temporary employment agencies or specialized leased labor firms. Overall, these workers have shorter contract durations and reduced job security; more irregular working hours; increased employment by third parties, such as temporary employment agencies; and a greater dependence on various forms of dependent self-employment, such as subcontracting, franchising, and informal work arrangements [2-5].

Unskilled manual work is considered an elementary occupation, and 1 of 9 major groups of occupations accord-

Received: February 27, 2020. Accepted: March 30, 2021.

Corresponding author: Yangho Kim, University of Ulsan College of Medicine, Ulsan University Hospital, Department of Occupational and Environmental Medicine, 290-3 Cheonha-dong, Dong-gu, Ulsan 44033, South Korea (e-mail: yanghokm@ulsan.ac.kr). 
ing to the Korean Standard Classification of Occupations (KSCO) [6] and the International Standard Classification of Occupations (ISCO) [7]. Workers who have elementary occupations perform unskilled manual work, only have short on-the-job training, and require minimal skills, although their jobs may require physical strength and/or endurance. Hence, unskilled manual workers can easily adapt to different elementary occupations if they have adequate physical strength. Elementary occupations include jobs in construction, mining, automobile driving, manufacturing, cleaning, security, food preparation, domestic chores, sales, agriculture and fisheries, and other service work. Unskilled manual workers accounted for $11.5 \%$ of all waged workers in Korea during 2017 [8]. Most unskilled manual workers in Korea tend to get elementary occupations after retirement from their primary jobs, at the age of about 50 years. Thus, unskilled employees who perform manual work tend to be older, have worse education and income, work fewer hours and for shorter durations, experience more ergonomic hazards, and have more physical and mental problems [9-11]. They are, therefore, considered to have precarious employment.

The status of these precarious workers often changes over time, and they often shift among being non-standard workers, lower-skilled workers employed in microenterprises, self-employed individuals without special skills or certifications, and temporarily unemployed persons $[2,3,5,12]$. Previous studies found that poor mental health was associated with precarious employment. In particular, Jang et al. [13] found that precarious workers were more likely to have depressive symptoms; Min [14] showed that part-time workers had a greater risk of suicide; Kim et al. [15] reported that part-time, temporary, and daily workers had worse mental health; and Ahn et al. [16] concluded that workers who had daily employment were more likely to experience depression and suicidal ideation.

However, very few studies have examined the mental health problems of unskilled manual workers. A previ- ous study conducted by the authors of this article found that workers who had unskilled and manual jobs were older and less educated, had lower incomes, worked fewer hours, and had more depressive feelings and suicidal ideation [9-11,16]. Another study showed that male unskilled manual workers with non-standard employment were more likely to experience occupational safety and health problems than other non-standard workers [17].

Most research on the mental health of workers has been based on 2 models - the demand-control-support (DCS) model [18] and the effort-reward imbalance (ERI) model [19]. However, the nature of work, industrial structures, and work processes were changed significantly during recent years and, thus, the use of non-standard contracts and job insecurity was increased [1,2]. In this rapidly changing work life, pre-existing mental healthrelated models such as job strain (from the DCS) or ERI may not be able to capture the psychosocial determinants of mental health in precarious workers [20,21]. Thus, the authors examined modifiable psychosocial work factors related to precarious workers such as long working time, abusive behaviors, a lack of job satisfaction and support from managers, and a bad social climate, in order to assess psychological well-being.

They first characterized the demographic, socioeconomic, and psychosocial work factors associated with unskilled manual work, and then identified the modifiable psychosocial factors that most affected the psychological wellbeing of these workers.

\section{MATERIAL AND METHODS}

\section{Data source}

This study analyzed data that was collected by the Korea Occupational Safety and Health Agency in June-September of 2017 for the fifth Korean Working Condition Survey (KWCS) [22]. The KWCS is a triennial survey that assesses exposure to adverse working conditions, workplace hazards, and health problems related to the 
workplace. The participants were representatives of workers in Korea aged $\geq 15$ years during the survey period. "Worker" was defined as working for pay or profit for $\geq 1 \mathrm{~h}$ during the week prior to the interview; any individual with a status of "retired," "unemployed," "a homemaker" or "a student" was not included. The study used multistage randomized sampling with stratification, and employed the same districts that were used in the 2010 census.

There were 50205 in-person household interviews, and data were weighted so that the participants' characteristics (region, locality, and place of residence; sex; age; employment status; and industry of employment) resembled those of the overall working population of Korea. Previous research confirmed the content validity and reliability of the KWCS [23].

\section{Study subjects and definitions}

Among 50205 interviewed subjects, foreign workers, self-employed persons, and employers were excluded. The study subjects were 37081 waged workers (i.e., "employees"). The occupational classes were: "managers, professionals, and clerks," "service and sales workers," and "skilled or unskilled manual workers." After categorization of the type of work as manual or non-manual, manual work was considered to be skilled or unskilled. Individuals with skilled manual work were in 3 of the 9 major groups in the KSCO [6] and the ISCO [7]: "skilled workers related to agriculture, forestry and fisheries," "craft and related trade workers," and "workers related to equipment, machine operating and assembling." Unskilled manual work was defined as "elementary occupations," as in the KSCO [6], and the major occupational group termed "elementary occupations" in the ISCO [7]. Then, nonmanual workers were categorized as "managers, professionals, and clerks" or "service and sales workers."

"Service and sales work" requires emotional labor, which was described in a previous study as "the management of feelings to create a publicly observable facial and bodily display" [24]. Emotional labor is, therefore, different from other types of non-manual work that require cognitive skills, such as that performed by "managers, professionals" and "clerks" (mental workers). "Service and sales workers" (emotional workers) often work in small shops, shopping malls, banks, hotels, and restaurants [25]. Each individual was categorized as having a contract for regular employment ( $\geq 1$ year), temporary employment (1 month-<1 year), or daily employment ( $<1$ month). After the survey was thoroughly described, each participant signed an informed consent agreement.

\section{Measurements \\ Dependent variable}

Psychological well-being was determined using the WHO Well-Being Index (WHO-5) [26]. This scale rates positive mood (good spirits and relaxation), vitality (being active and waking up fresh and rested), and general interest (being interested in things). The WHO-5 has 5 items that assess the presence or absence of well-being over the last 2 weeks, and each answer is scored $0-25$. An individual with a score of $<13$ was considered to have poor psychological well-being, and was recommended to be tested for depression [26].

\section{Independent variable (psychosocial work factors)}

Average weekly working time was classified as short working time $(<40 \mathrm{~h})$, moderate working time $(40-47 \mathrm{~h})$, long working time (48-59 h), or excessively long working time ( $\geq 60 \mathrm{~h}$ ).

An individual's satisfaction with his/her working conditions was determined by asking the following question: "On the whole, are you very satisfied, satisfied, not very satisfied, or not at all satisfied with the working conditions in your main paid job?" For the analysis, the responses of "very satisfied" and "satisfied" were reclassified as "satisfied," and the responses of "not very satisfied" and "not at all satisfied" as "not satisfied." 
Support from the manager was measured by asking if the manager:

- respected the employee as a person,

- gave the employee praise and recognition when he/she did a good job,

- was successful in getting people to work together,

- was helpful in getting the job done,

- provided useful feedback on the employee's work,

- encouraged and supported the employee's development.

The social climate at work was measured by asking if:

- the employees were appreciated when they did a good job,

- the management trusted the employees to do their work well,

- conflicts were resolved in a fair way,

- the work was distributed fairly,

- there was good cooperation between you and your colleagues,

- the employees generally trusted the management.

A 5-point Likert scale (1 - "strongly agree," 2 - "tend to agree," 3 - "neither agree nor disagree," 4 - "tend to disagree," and 5 - "strongly disagree") was used to score the answers to each of the 6 specific topics regarding support from managers and social climate, and a score above the median indicated "support from managers" or "a good social climate."

Subjective health was measured by the question: "How is your health in general?" with possible answers of "very good," "good," "fair," "bad" or "very bad." For the analysis, the responses of "very good" and "good" were reclassified as "good," the response of "fair" remained classified as "fair," and the responses of "bad" and "very bad" were reclassified as "bad."

Exposure to adverse social behaviors at work (from colleagues, superiors, or clients) was measured by asking the following questions: "Over the last month, during the course of your work, have you been subjected to any of the following: a) verbal abuse, b) unwanted sexual attention, c) threats, d) humiliating behaviors?" "Over the last year, during the course of your work, have you been subjected to any of the following: e) physical violence, f) sexual harassment, or g) bullying/harassment?" The response options for each of these were "yes" and "no", and a "yes" indicated "exposure to adverse social behavior."

\section{Covariates}

These data included sex, age in years $(<40,40-49,50-59$ or $\geq 60$ ), education (lower than high school, high school or higher than high school), monthly income in USD (<1000, 1000-1999, 2000-2999, 3000-3999 or $\geq 4000)$, duration of employment ( $<1$ year, 1-4, 5-9, 10-19 years or $\geq 20$ years), and employment in a regular job, temporary job or daily job.

\section{Statistical analysis}

The $\chi^{2}$ test was used to compare the different occupational classes, demographic factors, socioeconomic factors, and psychosocial work factors (Table 1). The odds ratio (ORs) and $95 \%$ confidence intervals (95\% CIs) for poor well-being from the WHO-5 were calculated using multiple logistic regression after adjustment for confounding using 2 models (model 1: age, education, and income; model 2: all model 1 factors and weekly working time, employment status, exposure to adverse social behavior, job satisfaction, support from manager, and social climate). An assessment of the interaction of gender with psychosocial work factors on poor psychological wellbeing was performed by adding several interaction variables to the logistic regression analysis: gender $\times$ occupational class, weekly working time, employment status, exposure to abusive behavior, a lack of job satisfaction, a lack of support from managers, and a bad social climate at work.

The presence of a statistically significant interaction thus indicated a gender difference for the effect of an inde- 


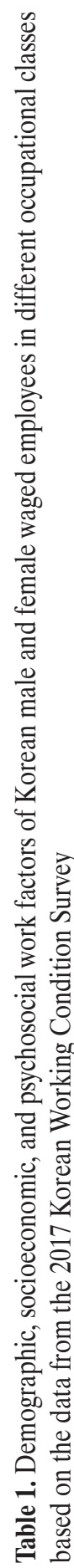

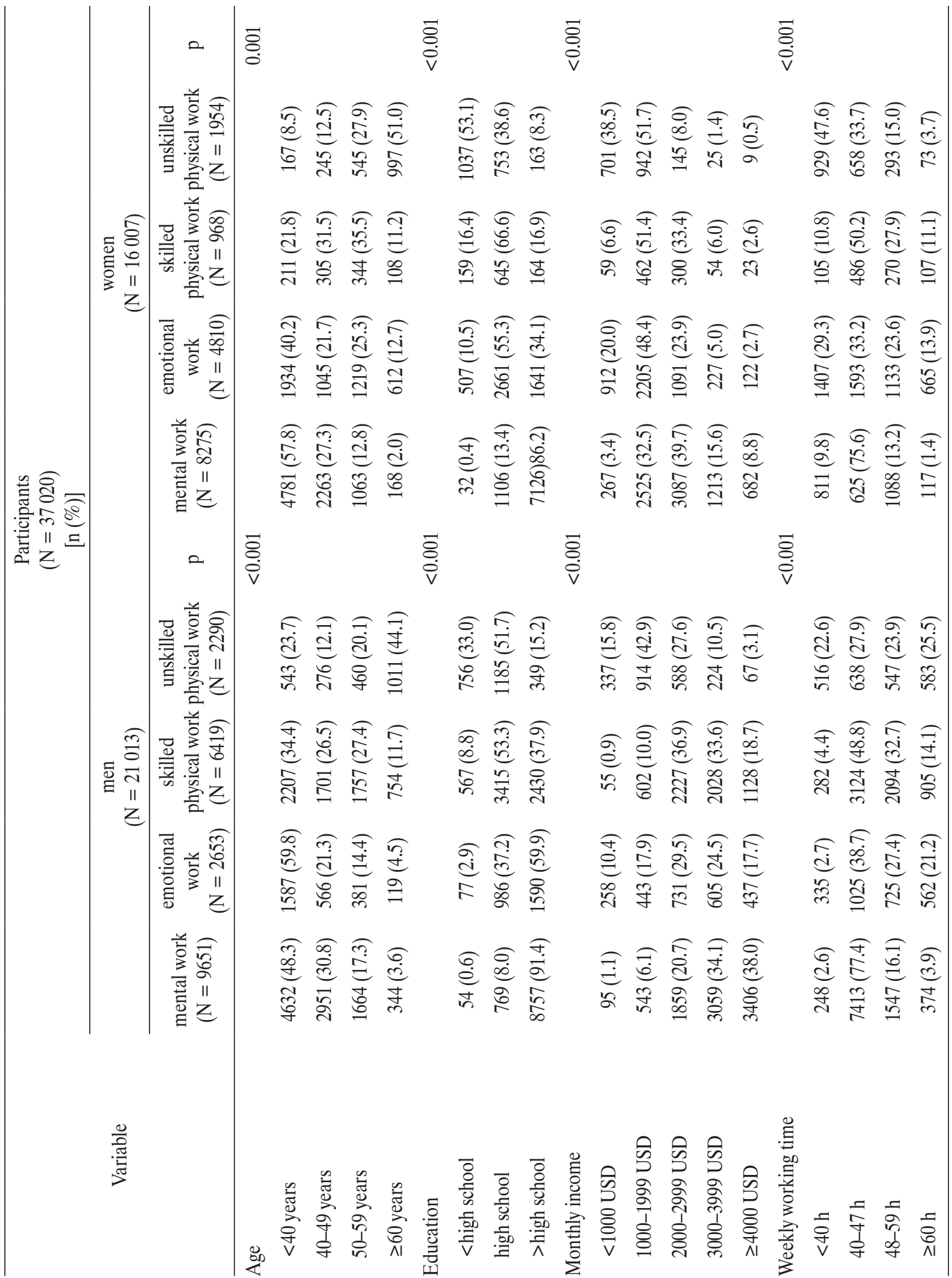




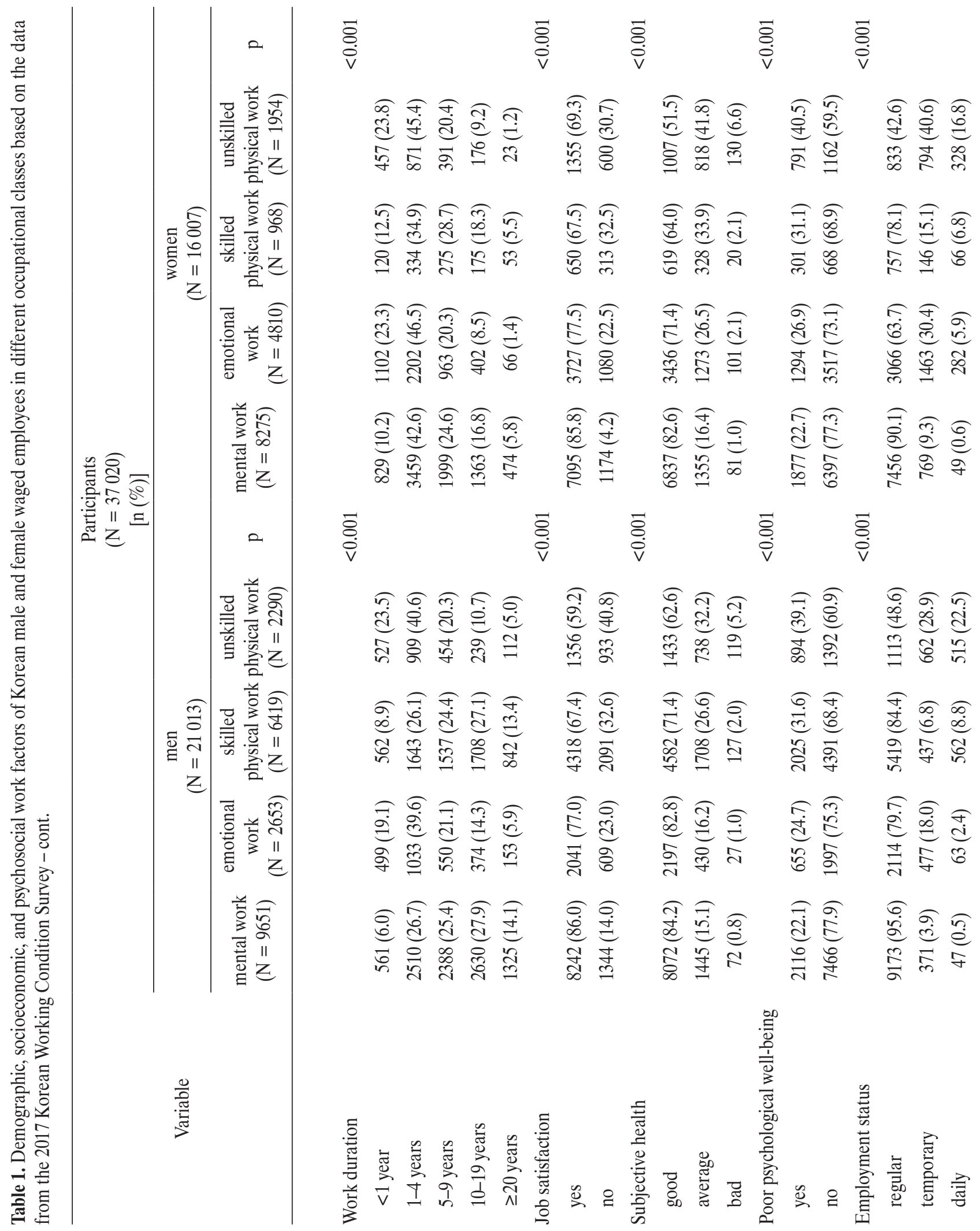




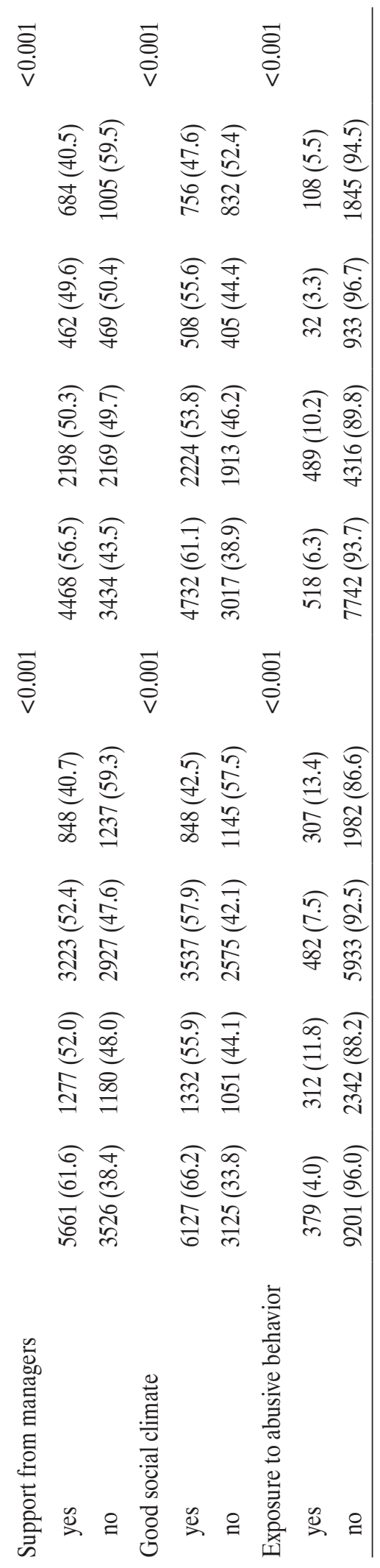

pendent variable on poor psychological well-being. In this case, ORs for conditional effects and ORs for main effects were calculated to compare the effects of independent variables according to gender. The absence of a significant interaction indicated that the independent variable had similar effects on poor psychological well-being in males and females. The SPSS v. 20 software was used for these statistical analyses, and a p-value of $<0.05$ was considered statistically significant. The Hayes PROCESS macro for SPSS was also used to determine whether the effect of psychosocial work factors (psychosocial work factors such as weekly working time, abusive behaviors, job satisfaction, support from managers, and a social climate) on poor psychological well-being varied in magnitude and nature as a function of occupational class after adjustment for age, sex, education, monthly income, employment status, and any other psychosocial work factors [27,28].

\section{RESULTS}

Table 1 summarizes the study population, with classification by gender and occupation. Among men, $45.8 \%$ were mental workers (managers, professionals, and clerks), $12.7 \%$ were emotional workers (service and sales workers), $30.6 \%$ were skilled manual workers, and $10.9 \%$ were unskilled manual workers (elementary occupations). Among women, $51.7 \%$ were mental workers, $30.0 \%$ were emotional workers, $6.0 \%$ were skilled manual workers, and $12.2 \%$ were unskilled manual workers.

Males and females had the same general relationships for many of the analyzed variables. In particular, in the class of unskilled manual work, both genders had higher proportions of workers who were elderly ( $\geq 60$ years old), less educated, and had low income. Both genders had higher proportions of workers who worked $<40 \mathrm{~h}$ weekly, higher proportions of individuals who worked for $<1$ year, lower proportions of workers with good subjective health, and higher proportions of workers with poor psychological well-being. Both genders also had lower proportions of 
support from managers and lower proportions of working in a good social climate.

However, there were some gender differences in job satisfaction and exposure to abusive behavior. Among males, fewer individuals who reported job satisfaction were unskilled manual workers; among females, fewer individuals who reported job satisfaction were skilled manual workers, followed by unskilled manual workers. Among males, more individuals exposed to abusive behavior at work were unskilled manual workers; among females, more individuals exposed to abusive behavior at work were service and sales workers.

A crude logistic regression model (Table 2) indicated that more emotional workers, skilled manual workers, and unskilled manual workers $(\mathrm{OR}=1.156,1.627$, and 2.265, respectively) reported poor psychological well-being than mental workers, but the interaction terms were not significant ( $p>0.05$ for all). In other words, the occupational class had similar adverse effects on the psychological wellbeing of males and females.

However, model 1 (a logistic regression model which accounted for age, income, and education) indicated statistical significance in the interaction terms. In other words, skilled manual workers who were male $(\mathrm{aOR}=1.330)$ had poorer psychological well-being than mental workers who were male, whereas skilled manual workers and mental workers who were female were equally likely to report poor psychological well-being. Relative to mental workers, those with unskilled manual jobs $(\mathrm{aOR}=1.452)$ had a greater probability of reporting poor psychological well-being, and the interaction terms were not significant. Workers aged $\geq 40$ years were more likely to have poor psychological well-being than those who were younger, and workers with high school or higher educational levels were less likely to have poor psychological well-being than those in the lowest education group. Workers in higher income groups were less likely to have poor psychological well-being than those in the lowest income group.
A logistic regression model that adjusted for all model 1 factors and for weekly working time, employment status, exposure to abusive behavior, job satisfaction, support from managers, and social climate (model 2 ) indicated that unskilled manual work was no longer related to psychological well-being for both genders, and that individuals who performed emotional work had a lower probability of poor well-being $(\mathrm{aOR}=0.762)$, with no statistical significance in the interaction terms. Female workers were less likely to have poor well-being $(\mathrm{aOR}=0.725)$ than male workers. Workers with the longest weekly working time ( $\geq 60 \mathrm{~h}$ ) were more likely to have poor well-being ( $\mathrm{aOR}=$ $1.324)$ compared to those who worked $<40 \mathrm{~h} /$ week. However, males and females had a significant difference in the interaction terms. In particular, males who worked $40-47 \mathrm{~h}(\mathrm{aOR}=0.815)$ were less likely to have poor psychological well-being than those who worked $<40 \mathrm{~h} /$ week, but weekly working time was unrelated to poor well-being in females.

The analysis of the employment status indicated that daily workers had a marginally significant increased risk of poor psychological well-being. However, the model $(\mathrm{p}<0.05)$ indicated that female temporary workers had a greater probability of poor psychological well-being than female regular workers. Females exposed to abusive behavior at work had a greater probability of reporting poor well-being $(\mathrm{aOR}=1.323)$, whereas exposure to abusive behavior at work was unrelated to wellbeing among males after adjustment for confounders $(\mathrm{p}<0.05)$. Workers who lacked job satisfaction, support from managers, and those in a bad social climate were more likely to report poor well-being with adjustment for confounding ( $p>0.05)$.

The authors also examined whether the effect of psychosocial work factors (psychosocial work factors such weekly working time, abusive behaviors, job satisfaction, support from managers, and social climate) on poor psychological well-being varied in magnitude and nature as 
Table 2. Multivariate logistic analysis of the association of poor psychological well-being with the occupational class, demographic factors, socioeconomic factors, and psychosocial work factors in Korean waged employees (the 2017 Korean Working Condition Survey)

\begin{tabular}{|c|c|c|c|}
\hline \multirow{2}{*}{ Variable } & \multirow{2}{*}{ OR $(95 \% \mathrm{CI})$} & \multicolumn{2}{|c|}{$\mathrm{aOR}(95 \% \mathrm{CI})$} \\
\hline & & model 1 & model 2 \\
\hline \multicolumn{4}{|l|}{ Occupational class } \\
\hline mental work & 1.0 (ref.) & 1.0 (ref.) & 1.0 (ref.) \\
\hline emotional work & $1.156(1.045-1.278)^{*}$ & $1.005(0.900-1.122)$ & $0.762(0.671-0.865)^{*}$ \\
\hline skilled physical work & $1.627(1.515-1.748)^{*}$ & $1.330(1.223-1.446)^{*}$ & $1.016(0.925-1.115)$ \\
\hline unskilled physical work & $2.265(2.056-2.495)^{*}$ & $1.452(1.289-1.637)^{*}$ & $0.925(0802-1.066)$ \\
\hline occupational class $\times$ gender & n.s. & $\begin{array}{c}\text { skilled physical } \\
\text { work } \times \text { gender } \\
\mathrm{p}<0.05 \text {; OR (men: } 1.330^{*} \\
\text { vs. women: } 1.051 \text { ) }\end{array}$ & n.s. \\
\hline \multicolumn{4}{|l|}{ Gender } \\
\hline women vs. men & $1.035(0.965-1.111)$ & $0.986(0.910-1.068)$ & $0.725(0.578-0.910)^{*}$ \\
\hline \multicolumn{4}{|l|}{ Age } \\
\hline$<40$ years & & 1.0 (ref.) & 1.0 (ref.) \\
\hline $40-49$ years & & $1.235(1.159-1.317)^{*}$ & $1.206(1.125-1.294)^{*}$ \\
\hline $50-59$ years & & $1.234(1.149-1.326)^{*}$ & $1.177(1.087-1.274)^{*}$ \\
\hline$\geq 60$ years & & $1.254(1.134-1.386)^{*}$ & $1.352(1.206-1.515)^{*}$ \\
\hline \multicolumn{4}{|l|}{ Education } \\
\hline lower than high school & & 1.0 (ref.) & 1.0 (ref.) \\
\hline high school & & $0.709(0.639-0.785)^{*}$ & $0.778(0.690-0.877)^{*}$ \\
\hline higher than high school & & $0.564(0.502-0.634)^{*}$ & $0.667(0.583-0.764)^{*}$ \\
\hline \multicolumn{4}{|l|}{ Monthly income } \\
\hline$<1000$ USD & & 1.0 (ref.) & 1.0 (ref.) \\
\hline 1000-1999 USD & & $1.055(0.955-1.165)$ & $0.945(0.818-1.092)$ \\
\hline 2000-2999 USD & & $0.926(0.833-1.031)$ & $0.842(0.720-0.986)^{*}$ \\
\hline 3000-3999 USD & & $0.874(0.777-0.983)^{*}$ & $0.862(0.730-1.018)$ \\
\hline$\geq 4000$ USD & & $0.838(0.739-0.950)^{*}$ & $0.901(0.757-1.071)$ \\
\hline \multicolumn{4}{|l|}{ Weekly working time } \\
\hline$<40 \mathrm{~h}$ & & & 1.0 (ref.) \\
\hline $40-47 \mathrm{~h}$ & & & $0.815(0.683-0.973)^{*}$ \\
\hline $48-59 \mathrm{~h}$ & & & $1.023(0.854-1.225)$ \\
\hline$\geq 60 \mathrm{~h}$ & & & $1.324(1.094-1.602)^{*}$ \\
\hline weekly working hours $\times$ gender & & & $\begin{array}{c}(40-47 \mathrm{~h}) \times \text { gender, } \\
\mathrm{p}<0.05 \text {; OR (men: } 0.815^{*} \\
\text { vs. women: } 1.102)\end{array}$ \\
\hline
\end{tabular}


Table 2. Multivariate logistic analysis of the association of poor psychological well-being with the occupational class, demographic factors, socioeconomic factors, and psychosocial work factors in Korean waged employees (the 2017 Korean Working Condition Survey) - cont.

\begin{tabular}{|c|c|c|c|}
\hline \multirow{2}{*}{ Variable } & \multirow{2}{*}{ OR $(95 \% \mathrm{CI})$} & \multicolumn{2}{|c|}{$\mathrm{aOR}(95 \% \mathrm{CI})$} \\
\hline & & model 1 & model 2 \\
\hline \multicolumn{4}{|l|}{ Employment status } \\
\hline regular & & & 1.0 (ref.) \\
\hline temporary & & & $0.949(0.826-1.089)$ \\
\hline daily & & & $1.171(0.995-1.377)$ \\
\hline employment status $\times$ gender & & & $\begin{array}{c}\text { temporary } \\
\text { employment } \times \text { gender, } \\
\text { p < 0.05; OR (men: } 0.948 \\
\text { vs. women: } 1.194^{*} \text { ) }\end{array}$ \\
\hline Exposure to abusive behavior & & & $1.016(0.890-1.160)$ \\
\hline $\begin{array}{l}\text { exposure to abusive } \\
\text { behavior } \times \text { gender }\end{array}$ & & & $\begin{array}{c}\text { exposure to abusive } \\
\text { behavior } \times \text { gender, } \mathrm{p}<0.05 \text {; } \\
\text { OR (men: } 1.016 \\
\left.\text { vs. women: } 1.323^{*}\right)\end{array}$ \\
\hline Lack of job satisfaction & & & $1.655(1.525-1.795)^{*}$ \\
\hline lack of job satisfaction $\times$ gender & & & n.s. \\
\hline Lack of support from managers & & & $1.359(1.252-1.476)^{*}$ \\
\hline $\begin{array}{l}\text { lack of support from } \\
\text { managers } \times \text { gender }\end{array}$ & & & n.s. \\
\hline Bad social climate at work & & & $1.982(1.825-2.152)^{*}$ \\
\hline bad social climate at work $\times$ gender & & & n.s. \\
\hline
\end{tabular}

n.s. - non-significant; $x$ - interaction.

$* \mathrm{p}<0.05$.

a function of the occupational class after adjustment for age, sex, education, monthly income, employment status, and any other psychosocial work factors than predictor (Table 3, Figure 1). Among the 5 psychosocial work factors, the effect of weekly working time, job satisfaction, and abusive behaviors on poor psychological wellbeing depended on the occupational class, but the effect of support from managers, and social climate on poor psychological well-being did not. For unskilled manual workers, the probability of poor psychological well-being was the lowest in the weekly working time (40-47 h), whereas for mental workers, the longer the weekly work- ing time, the greater the probability of poor psychological well-being.

The association between a lack of job satisfaction and poor psychological well-being was greater in unskilled manual workers than that in other occupational class. For unskilled manual workers, poor psychological well-being was unrelated to exposure to abusive behavior, whereas, for mental workers, poor psychological well-being was positively associated with exposure to abusive behavior. However, poor psychological well-being was positively associated with a lack of support from managers and a bad social climate, irrespective of the occupational class. 
Table 3. B coefficients (95\% CIs) of poor psychological well-being with interaction terms after adjustment for age, sex, education, monthly income, employment status, and other work psychosocial factors in Korean waged employees

(the 2017 Korean Working Condition Survey)

\begin{tabular}{|c|c|c|c|c|}
\hline \multirow{2}{*}{ Variable } & \multicolumn{4}{|c|}{ B coefficients $(95 \% \mathrm{CI})$} \\
\hline & mental work & emotional work & skilled manual work & unskilled manual work \\
\hline \multicolumn{5}{|c|}{$\begin{array}{l}\text { Interaction (weekly } \\
\text { working time } \\
\times \text { occupational } \\
\text { class) }{ }^{* * *}\end{array}$} \\
\hline \multicolumn{5}{|c|}{ weekly working time } \\
\hline$<40 \mathrm{~h}$ & 0 (ref.) & 0 (ref.) & 0 (ref.) & 0 (ref.) \\
\hline $40-47 \mathrm{~h}$ & $0.053(-0.168-0.274)$ & $0.067(-0.126-0.260)$ & $-0.233(-0.522-0.055)$ & $-0.322(-0.528-(-0.116))^{* *}$ \\
\hline $48-59 \mathrm{~h}$ & $0.345(0.099-0.590)^{* *}$ & $0.080(-0.119-0.279)$ & $-0.267(-0.564-0.030)$ & $-0.174(-0.407-0.060)$ \\
\hline$\geq 60 \mathrm{~h}$ & $0.792(0.452-1.132)^{* * *}$ & $0.367(0.152-0.582)^{* *}$ & $0.264(-0.059-0.586)$ & $0.018(-0.225-0.260)$ \\
\hline \multicolumn{5}{|c|}{$\begin{array}{l}\text { Interaction (job } \\
\quad \text { satisfaction } \\
\quad \times \text { occupational class)* }\end{array}$} \\
\hline \multicolumn{5}{|l|}{ job satisfaction } \\
\hline yes & 0 (ref.) & 0 (ref.) & 0 (ref.) & 0 (ref.) \\
\hline no & $0.515(0.389-0.641)^{* * *}$ & $0.438(0.305-0.571)^{* * *}$ & $0.449(0.312-0.585)^{* * *}$ & $0.714(0.560-0.869)^{* * *}$ \\
\hline \multicolumn{5}{|c|}{$\begin{array}{l}\text { Interaction (exposure } \\
\text { to abusive behavior } \\
\times \text { occupational } \\
\text { class)** }\end{array}$} \\
\hline \multicolumn{5}{|c|}{$\begin{array}{l}\text { exposure to abusive } \\
\text { behavior }\end{array}$} \\
\hline yes & 0 (ref.) & 0 (ref.) & 0 (ref.) & 0 (ref.) \\
\hline no & $-0.426(-0.620-(-0.232))^{* * *}$ & $-0.019(-0.215-0.177)$ & $0.043(-0.215-0.301)$ & $0.062(-0.194-0.318)$ \\
\hline
\end{tabular}

$x$ - interaction.

${ }^{*} \mathrm{p}<0.05 ; * \mathrm{p}<0.01 ; * * \mathrm{p}<0.001$.

\section{DISCUSSION}

The authors found several significant differences between males and females in the variables of weekly working time, employment status, and exposure to abusive behavior. Females were less likely to report poor well-being than males. However, males and females were similar in terms of a lack of job satisfaction, a lack of support from managers, and a bad social climate at the workplace.

There were fewer male service and sales workers, and fewer female skilled manual workers. In addition, indi- viduals who were considered as unskilled manual workers were older, had worse education and income, worked fewer hours weekly and had shorter work duration, had temporary or daily employment, and reported poor subjective health and well-being. Furthermore, unskilled manual workers experienced more psychosocial hazards, such as abusive behavior at work, a lack of job satisfaction, a lack of support from managers, and a bad social climate. In Korea, most unskilled manual workers tend to get elementary occupations after retirement from their primary 

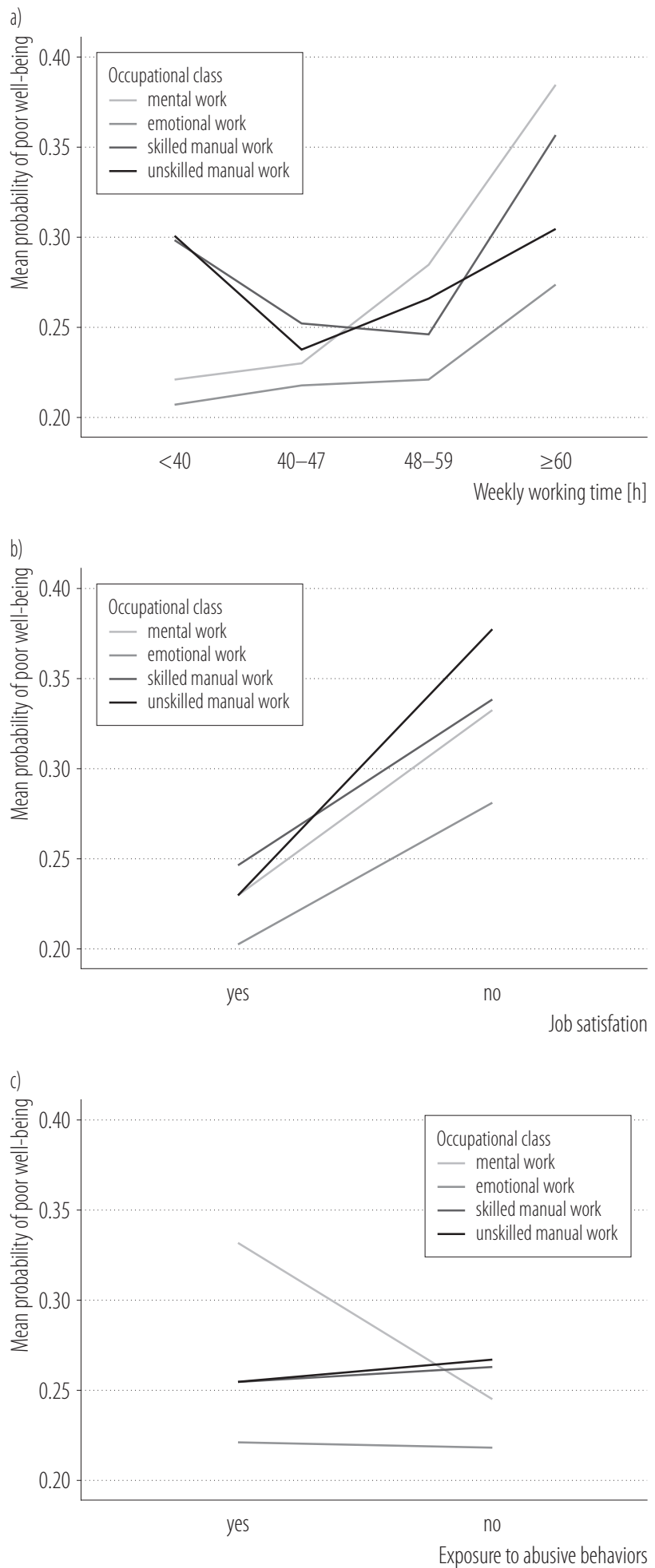

Figure 1. Mean probability of poor psychological well-being according to a) weekly working time b) job satisfaction, c) exposure to abusive behaviors by occupational classes jobs at the age of about 50 years [8]. The present study showed that unskilled workers aged $\geq 50$ years accounted for most of the unskilled workers $(66.2 \%$ of males and $78.9 \%$ of females). The authors' previous studies found that individuals employed as unskilled manual workers were older, less educated, had lower incomes, worked fewer hours weekly, and reported depressive feelings and suicidal ideation [9-11]. Another study showed that males who were employed as unskilled manual workers and had non-standard employment were more vulnerable to occupational safety and health problems than other non-standard workers [17].

However, the multivariate analysis which controlled for demographic, socioeconomic, and psychosocial work factors indicated that unskilled manual work was no longer significantly associated with poor psychological well-being. Thus, the poor psychological well-being of unskilled manual workers is not intrinsic to this type of work; instead, it arises from exposure to multiple unfavorable psychosocial work factors (employment status, exposure to abusive behavior at work, a lack of job satisfaction or support from managers, and a bad social climate) that are associated with unskilled manual work.

In the present study, unskilled manual workers had a greater association between a lack of job satisfaction and poor psychological well-being than those representing other occupational classes. This is a novel finding in the present study. Prior publications showed that low job satisfaction was most strongly associated with mental and psychological problems $[29,30]$. In addition, the sixth European Working Conditions Survey [31] grouped workers into 5 job profiles (21\% high flying jobs, $25 \%$ smooth running jobs, $21 \%$ active manual jobs, $13 \%$ under pressure jobs, and $20 \%$ poor quality jobs). Poor quality jobs, to which $54 \%$ of essential occupations were subject, were associated with lower levels of subjective well-being, satisfaction with working conditions, work-life balance, and sustainability of work [31]. 
For unskilled manual workers, the probability of poor psychological well-being was greater in the short working time $(<40 \mathrm{~h})$ as well as in the long working time $(\geq 60 \mathrm{~h})$ whereas for non-manual workers, poor psychological wellbeing was greater in long working time $(\geq 60 \mathrm{~h})$ in the present study. These results regarding non-manual workers are similar to those of previous publications which also reported an association of long working time with poor mental health [32,33]. However, unskilled manual workers who were older, had worse education and income, and had temporary or daily employment, compared to those representing other occupational classes, were motivated to increase their incomes by simply working more hours [22]. These rewards may increase well-being in terms of working time (40-47 h). However, working long hours ( $\geq 60 \mathrm{~h} /$ week) may have an adverse impact on sleep and work-life balance, eventually leading to poor psychological well-being.

For unskilled manual workers, poor psychological well-being was unrelated to exposure to abusive behavior, whereas for mental workers, poor psychological well-being was positively associated with exposure to abusive behavior. Compared to these findings, workers who experienced discrimination or sexual harassment had more psychological problems in previous studies [34,35].

In the present study, poor psychological well-being was positively associated with a lack of support from managers and a bad social climate, irrespective of the occupational class. Other research found that workers who reported organizational injustices had more psychological problems [36,37]. Previous studies showed that a lack of support from managers was related to poor psychological well-being [29,30].

The present study is the first to evaluate factors related to the psychological well-being of unskilled manual workers and, therefore, has potential public health implications. The authors found that the poor psychological well-being of unskilled manual workers is not an intrinsic characteristic of this type of work, but is actually attributable to the unfavorable psychosocial work factors associated with this type of work. Thus, modification of psychosocial work factors may improve the psychological well-being of unskilled manual workers. Employers should, therefore, improve the working conditions, and make an effort to establish a good social climate at the workplace, and managers should provide more support for these workers. As a measure specific to unskilled manual workers, employers should encourage them not to work excessively, rather than simply shortening their working time.

A major strength of this study is that it was based on representative survey data from the KWCS. The KWCS covers all adult workers in Korea and employs rigorous quality control measures.

This study, nonetheless, also has some limitations. First, the study had a cross-sectional design, making it impossible to infer causality because of the possibility of reverse causality or unknown intermediary factors that were responsible for the associations. The authors also did not examine the temporal relationships of performing unskilled manual work with poor well-being. Thus, the "healthy worker effect" could explain the association between unskilled manual work and poor mental health if individuals who had prior mental health problems were more likely to be employed as unskilled manual workers. However, a previous study of this topic reported that adverse work conditions had a greater impact on poor health, thus rejecting the "healthy worker effect" as an explanation [38]. Nonetheless, prospective studies are needed to confirm causality in the associations identified here. Another limitation is that the authors used data that was self-reported by workers rather than objective findings.

\section{CONCLUSIONS}

The authors characterized the demographic, socioeconomic, and psychosocial work factors associated with unskilled manual work, and identified modifiable psychosocial factors that affected the psychological well-being of 
these workers. In particular, the effect of weekly working time, job satisfaction, and abusive behaviors on poor psychological well-being depended on the occupational class. Employers should, therefore, improve the working conditions, and make an effort to establish a good social climate at the workplace, and managers should provide more support for these workers to improve the psychological wellbeing of unskilled manual workers.

\section{REFERENCES}

1. Benach J, Vives A, Amable M, Vanroelen C, Tarafa G, Muntaner C. Precarious employment: understanding an emerging social determinant of health. Annu Rev Public Health. 2014;35:229-53.

2. Quinlan M. The effects of non-standard forms of employment on worker health and safety. [Internet] Geneva: ILO; 2015 [cited 2020 Jan 27]. Available from: https://www.ilo. org/wcmsp5/groups/public/---ed_protect/---protrav/---travail/ documents/publication/wcms_443266.pdf.

3. Quinlan M, Mayhew C, Bohle P. The global expansion of precarious employment, work disorganization, and consequences for occupational health: a review of recent research. Int J Health Services. 2001;31(2):335-414.

4. Brenner MH, Andreeva E, Theorell T, Goldberg M, Westerlund $\mathrm{H}$, Leineweber $\mathrm{C}$, et al. Organizational downsizing and depressive symptoms in the European recession: the experience of workers in France, Hungary, Sweden and the United kingdom. PLoS One. 2014;9(5):e97063, https://doi.org/ 10.1371/journal.pone.0097063.

5. International Labour Office [Internet]. Geneva: The Office; 2016 [cited 2020 Jan 27]. Non-standard employment around the world: Understanding challenges, shaping prospects. Available from: https://www.ilo.org/wcmsp5/groups/public/ @dgreports/@dcomm/@publ/documents/publication/wcms_ 534326.pdf.

6. Statistics Korea [Internet]. Statistics Korea; 2016 [cited 2019 Jan 4]. [Korean Standard Classification of Occupations (KSCO)]. Available from: http://kssc.kostat.go.kr/. Korean.
7. International Labour Office [Internet]. Geneva: The Office; 2012 [cited 2020 January 27]. International standard classification of occupations: ISCO-88. Available from: http://www. ilo.org/public/english/bureau/stat/isco/isco08/index.htm.

8. Statistics Korea [Internet]. Statistics Korea; 2018 [cited 2019 Jan 4]. [Economically active population survey]. Available from: http://kosis.kr/statisticsList/statisticsList_01List. jsp?vwcd $1 / 4$ MT_ZTITLE\&parentId $1 / 4$ B. Korean.

9. Ahn J, Kim NS, Lee BK, Park J, Kim Y. Relationship of Occupational Category with Risk of Physical and Mental Health Problems. Saf Health Work. 2019;10(4):504-11, https://doi. org/10.1016/j.shaw.2019.07.007.

10. Park J, Park JS, Han B, Kim Y. Vulnerability of employees in businesses with fewer than five workers (micro-enterprises) to occupational safety and health problems. Am J Ind Med. 2017;60(12):1056-65, https://doi.org/10.1002/ajim.22783.

11. Park J, Kim SG, Park JS, Han B, Kim KB, Kim Y. Hazards and health problems in occupations dominated by aged workers in South Korea. Ann Occup Environ Med. 2017;29:27, https://doi.org/10.1186/s40557-017-0177-9.

12. Fashoyin T, Tiraboschi M, Sargeant M, Ori M. Vulnerable workers and precarious working: Cambridge: Cambridge Scholars Publishing; 2014.

13. Jang S-Y, Jang S-I, Bae H-C, Shin J, Park E-C. Precarious employment and new-onset severe depressive symptoms: a population-based prospective study in South Korea. Scand J Work Environ Health. 2015:329-37.

14. Min K-B, Park S-G, Hwang SH, Min J-Y. Precarious employment and the risk of suicidal ideation and suicide attempts. Prev Med. 2015;71:72-6, https://doi.org/https://doi. org/10.1016/j.ypmed.2014.12.017.

15. Kim IH, Khang YH, Cho SI, Chun H, Muntaner C, Health P. Gender, professional and non-professional work, and the changing pattern of employment-related inequality in poor self-rated health, 1995-2006 in South Korea. J Prev Med Public Health. 2011;44(1):22-31.

16. Ahn J, Kim N, Lee B-K, Park J, Kim Y. Non-Standard Workers Have Poorer Physical and Mental Health Than Standard 
Workers. J Occup Environ Med. 2019;61(10):e413-21, https:// doi.org/10.1097/JOM.0000000000001682.

17. Park J, Han B, Park J-S, Park EJ, Kim Y. Nonstandard workers and differential occupational safety and health vulnerabilities. Am J Ind Med. 2019;62(8):701-15, https://doi.org/ 10.1002/ajim.22997.

18. Karasek RA Jr. Job demands, job decision latitude, and mental strain: Implications for job redesign. Admin Sci Quart. 1979:285-308.

19. Siegrist J. Adverse health effects of high-effort/low-reward conditions. J Occup Health Psychol. 1996;1(1):27-41, https:// doi.org/10.1037//1076-8998.1.1.27.

20. Park J, Kim Y. Workers With Different Employment Status Have Different Exposures to Work Stressors and Different Responses to Identical Work Stressors. J Occup Environ Med. 2020;62(12):e710-5, https://doi.org/10.1097/jom.0000 000000002035 .

21. De Jonge J, Bosma H, Peter R, Siegrist J. Job strain, effortreward imbalance and employee well-being: a large-scale cross-sectional study. Social Sci Med. 2000;50(9):1317-27.

22. The 5th Korean Working Conditions Survey. Ulsan: Korea Occupational Safety and Health Agency; 2019.

23. Kim YS, Rhee KY, Oh MJ, Park J. The validity and reliability of the second Korean working conditions survey. Saf Health Work. 2013;4(2):111-6, https://doi.org/10.1016/ j.shaw.2013.05.001.

24. Hochschild AR. The managed heart: Commercialization of human feeling. Berkeley: University of California Press; 1991.

25. De Castro AB, Agnew J, Fitzgerald ST. Emotional labor: relevant theory for occupational health practice in post-industrial America. AAOHN J. 2004;52(3):109-15.

26. World Health Organization. WHO (Five) Well-Being Index. Geneva: The Organization; 1998.

27. Hayes AF. Introduction to mediation, moderation, and conditional process analysis: A regression-based approach. New York, NY: Guilford Publications; 2017.

28. Hayes AF, Rockwood NJ. Regression-based statistical mediation and moderation analysis in clinical research:
Observations, recommendations, and implementation. Behaviour Res Therapy. 2017;98:39-57, https://doi.org/https:// doi.org/10.1016/j.brat.2016.11.001.

29. Faragher EB, Cass M, Cooper CL. The relationship between job satisfaction and health: a meta-analysis. Occup Environ Med. 2005;62(2):105-12, https://doi.org/10.1136/oem. 2002.006734.

30. Park J, Han B, Kim Y. Association of Job Satisfaction and Security with Subjective Health and Well-Being in Korean Employees. J Occup Environ Med. 2018;60(10):e525-32, https://doi.org/10.1097/jom.0000000000001418.

31. Eurofound. Sixth European working conditions survey-overview report (2017 update). Luxembourg: Publications Office of the European Union; 2017.

32. Virtanen M, Ferrie JE, Singh-Manoux A, Shipley MJ, Stansfeld SA, Marmot MG, et al. Long working hours and symptoms of anxiety and depression: a 5-year follow-up of the Whitehall II study. Psychol Med. 2011;41(12):2485-94, https://doi.org/10.1017/s0033291711000171.

33. Virtanen M, Stansfeld SA, Fuhrer R, Ferrie JE, Kivimaki M. Overtime work as a predictor of major depressive episode: a 5-year follow-up of the Whitehall II study. PLoS One. 2012;7(1):e30719, https://doi.org/10.1371/journal.pone. 0030719.

34. Hogh A, Henriksson ME, Burr H. A 5-year follow-up study of aggression at work and psychological health. Intern J Behav Med. 2005;12(4):256-65, https://doi.org/10.1207/s15327 558ijbm1204_6.

35. Willness CR, Steel P, Lee K. A meta-analysis of the antecedents and consequences of workplace sexual harassment. Personnel Psychol. 2007;60(1):127-62.

36. Ferrie JE, Head J, Shipley MJ, Vahtera J, Marmot MG, Kivimaki M. Injustice at work and incidence of psychiatric morbidity: the Whitehall II study. Occup Environ Med. 2006;63(7):443-50, https://doi.org/10.1136/oem.2005. 022269 .

37. Ndjaboue R, Brisson C, Vezina M. Organisational justice and mental health: a systematic review of prospective 
studies. Occup Environ Med. 2012;69(10):694-700, https:// doi.org/10.1136/oemed-2011-100595.

38. Carrieri V, Novi CD, Jacobs R, Robone S. Insecure, sick and unhappy? Well-being consequences of temporary employment contracts. In: Polachek SW, Tatsiramos K, editors. Factors Affecting Worker Well-being: The Impact of Change in the Labor Market. Bingley: Emerald Group Publishing Limited; 2014. p. 157-93.

This work is available in Open Access model and licensed under a Creative Commons Attribution-NonCommercial 3.0 Poland License - http://creativecommons.org/ licenses/by-nc/3.0/pl/deed.en. 